\title{
THE COMPREHENSIVE AND INTERACTION EFFECT OF EIGHT CULTIVATION METHODS ON WATER CONSUMPTION, WATER USE EFFICIENCY, AND MAIZE (ZEA MAYS L.) YIELDS IN THE ARID REGION OF NORTHERN CHINA
}

\author{
LiU, H. T. ${ }^{1,2,3}-$ ZHENG, X. Q. ${ }^{2 *}-$ CHEN, J. F. ${ }^{2}$ - HUANG, X. F. ${ }^{1,3}$ - HuANG, M. J. ${ }^{1,3}-$ WANG, J. L. $^{1}$ \\ ${ }^{1}$ Shanxi Academy of Agricultural Sciences Arid Farming Research Center \\ Taiyuan, Shanxi 030031, China \\ (phone: +86-351-7125-695; fax: +86-351-7135-600) \\ ${ }^{2}$ College of Water Resources and Engineering, Taiyuan University of Technology \\ Taiyuan, Shanxi 030024, China \\ ${ }^{3}$ Organic Dry Farming of Shanxi Province Key Laboratory \\ Taiyuan, Shanxi 030031, China \\ *Corresponding author \\ e-mail: zhengxiuqing@tyut.edu.cn \\ (Received 22 ${ }^{\text {nd }}$ Dec 2019; accepted $23^{\text {rd }}$ Mar 2020)
}

\begin{abstract}
Water resource crises have become the main factor limiting agricultural development in the arid and semi-arid regions of northern China. Accordingly, water saving agriculture has been a focus of researchers to improve the comprehensive use efficiency of limited water resources. The present study used the Uniform Design and examined the comprehensive and interaction effect of eight cultivation methods, including irrigation amount (IA), growth stages of irrigation (GI), sowing date (SD), planting density (PD), base nitrogen (BN), base phosphorus (BPS), base potassium (BPM), and nitrogen topdressing (NT) on water consumption (WC), water use efficiency (WUE), and maize (Zea mays L.) yields. Three key results were observed. (1) WC showed an significant positive correlation with IA, and the interaction effect of IA and GI on WC was significant and had the strongest effect. (2) WUE showed a significant positive correlation with PD, and the interaction effect of BPS and GI on WUE was significant. (3) An optimizing statistical model was used to maximize yield based on cultivation methods as a reference for agricultural practices. Overall, this research indicated that efforts to optimize cultivation methods to increase yield should first focus on optimizing IA and GI, with optimized irrigation management occurring secondarily. The present findings provide the foundation for improving both comprehensive water resource use efficiency and maize production.
\end{abstract}

Keywords: water resource, irrigation, planting density, agricultural factors, Uniform Design

\section{Introduction}

Agricultural production in the arid and semiarid regions of northern China has been limited by current water resource crises. Arid and semi-arid regions now account for $52.5 \%$ of the total landmass in China, and these regions play critical roles in grain production (Yang et al., 2016). However, increasing demand on global food supplies (Zeng et al., 2018) and water shortages are the primary problems occurring in arid agricultural regions (Zhang et al., 2018). Agriculture is a major consumer of water in such areas, and efficient agricultural water use is critical for sustaining and maximizing the benefits of limited water resources. Agricultural water resources will continue to be reduced by drought associated with climate change, nonsustainable groundwater use, and increasing competition from municipal, environmental, and industrial water needs (Han et al., 2016). Consequently, to achieve a delicate balance between 
water use and crop yield, increased crop water use efficiency, i.e., making less water produce higher yields, is a key objective in improving the productivity of agriculture in arid regions (Feng et al., 2019).

Water consumption, water use efficiency, and maize (Zea mays L.) yields are not only impacted by climate factors, but also have close relationships with agricultural methods, including tillage methods, mulch application, irrigation techniques, and planting density. Previous studies have revealed several relevant findings: deep plowing techniques can improve the water storage ability of soil and promote maize root to better absorb deep soil water, thus improving water use efficiency (Liu et al., 2013; Zhao et al., 2014); the negative influence of no-tillage becomes noticeable after 3 years, leading to significantly lower yield compared to plow tillage in northeastern Germany (Huynh et al., 2019); conservation agriculture can improve soil water content by reducing evaporation compared to conventional tillage (Ahadi et al., 2013); minimum tillage with optimum irrigation is evaluated as the best options for continuous maize cultivation in the red brown terrace soil without any yield penalty in Bangladesh (Sayed et al., 2019). Residue mulch decreased maximum soil temperature by $3.5-8.5^{\circ} \mathrm{C}$ resulting in better root growth in north-west India (Rajbir and Arora, 2019); plastic mulch can reduce wasteful crop water evaporation, thereby accelerating plant growth and maize maturation, ultimately increasing WUE and yield (Fan et al., 2017; Dong et al., 2018; Yang et al., 2018). Yet, maize characteristics often exhibit a parabolic relationship with field water consumption (Pereira et al., 2012; Zhang et al., 2014). In southern Italy, suitable irrigation strategies should be adopted in relation to the crop, soil characteristics and rainfall regime (Cucci et al., 2019); Irrigation and rainfall type can also impact field water evapotranspiration and yield, with water consumption increasing as irrigation volumes are added for a given irrigation frequency (Dong et al., 2014); when water is scarce, a $60 \%$ lower limit for relative soil moisture was recommended for use with conventional furrow irrigation (Wang et al., 2015). Different planting methods also lead to differences in the canopy structure. The intensity and degree of the available light in the canopy will induce changes in the structure and physiological characteristics of maize leaves (Liu et al., 2012). High planting density increased water use efficiency (by 13\%) under irrigation but decreased water use efficiency (by 17\%) under rainfed conditions in semi-arid Kenya (Ogola et al., 2007); with the increase of planting density in arid regions in China, the plant height of maize was a little different at the jointing stage and significant decreased at heading stage in normal years; and in wet year, the plant height of maize showed a rising tendency at jointing stage or heading stage (Zhang et al., 2014). Sowing date and planting density had significant interaction on the number and depth of deflated grains, but it had little effect on the number of grains and bald tip. Early sowing can delay the growth process of maize and prolong the growth period. With the delay of sowing date, the growth process was accelerated (Yu et al., 2013).

Above all, most studies focused on single or double cultivation factors effect on maize growth and production, However, few studies have focused on the comprehensive and interaction effects of multiple cultivation factors on water consumption, water resource utilization, and maize yields in the northern arid region of China, and due to heavy workload, the practice of multiple cultivation factors experiment was very difficult.

Thus, this study used a Uniform Design that combined eight cultivation methods: irrigation amount (IA), growth stages of irrigation (GI), sowing date (SD), planting density (PD), base nitrogen (BN), base phosphorus (BPS), base potassium (BPM), and nitrogen topdressing (NT) at the experimental field, and was undertaken at a Jinzhong Basin study site in Shanxi, which is a representative arid area of northern China. We assessed the effects of 
these eight cultivation methods on water consumption (WC), water use efficiency (WUE), and maize yield using correlation analyses. In addition to characterizing correlations, we also assessed interaction effects. This research forms the basis for improving both comprehensive water resource utilization and maize production efficiency in the arid regions of northern China.

\section{Materials and Methods}

\section{Experimental site}

The field experiment was conducted in 2016 at a site in Dongyang township, Yuci district, Jinzhong City, Shanxi Province, China. This region is located in the Xiao River alluvial plain within the Jinzhong Basin $\left(42^{\circ} 37^{\prime} \mathrm{N}, 112^{\circ} 40^{\prime} \mathrm{E}\right)$, a traditional area of grain and vegetable production. The climate conditions are continental monsoon type in a temperate zone, with four distinct seasons throughout the year, i.e., hot and rainy summers, cold and dry winters, and short spring and autumn seasons. The mean annual sunshine duration and mean annual air temperature are $2639 \mathrm{~h}$ and $9.8^{\circ} \mathrm{C}$, respectively. The mean temperatures in January and July are $-6.1^{\circ} \mathrm{C}$ and $23.5^{\circ} \mathrm{C}$, respectively. The mean annual precipitation is $430.2 \mathrm{~mm}$, with the highest annual precipitation being $624.9 \mathrm{~mm}$. The mean annual frost-free season was 154 days (Shanxi Statistical Yearbook, 2016). The soil type is moist soil with a pH of 8.0, and the basic soil physical properties are summarized in Table 1. The amounts of organic matter, total nitrogen, available nitrogen, available phosphorus, and available potassium were $17.4 \mathrm{~g} \mathrm{~kg}^{-1}$, $1.95 \mathrm{~g} \cdot \mathrm{kg}^{-1}, 119.5 \mathrm{mg} \cdot \mathrm{kg}^{-1}, 11.6 \mathrm{mg} \cdot \mathrm{kg}^{-1}, 241.9 \mathrm{mg} \bullet \mathrm{kg}^{-1}$, respectively.

Table 1. Basic physical soil properties of the experimental site

\begin{tabular}{c|c|c|c|c}
\hline Soil depth $(\mathbf{c m})$ & Soil texture & Bulk density $\mathbf{( g / c m 3})$ & Field capacity $(\mathbf{V} \%)$ & Wilting point $(\mathbf{V} \%)$ \\
\hline $0-20$ & clay soil & 1.22 & 32.7 & 11.6 \\
$20-40$ & clay soil & 1.47 & 30.9 & 14.0 \\
$40-60$ & sandy clay & 1.39 & 31.6 & 11.9 \\
$60-80$ & sandy loam & 1.37 & 32.9 & 7.1 \\
$80-100$ & clay sandy & 1.42 & 35.9 & 10.3 \\
$100-120$ & clay sandy & 1.41 & 33.4 & 11.9 \\
$120-140$ & clay soil & 1.41 & 33.3 & 13.3 \\
$140-160$ & clay soil & 1.41 & 33.3 & 13.3 \\
$160-180$ & clay soil & 1.41 & 33.3 & 13.3 \\
$180-200$ & clay soil & 1.41 & 33.3 & 13.3 \\
\hline
\end{tabular}

During maize growing season of experiment from April to October, the mean daily air temperature ranged from $7.9^{\circ} \mathrm{C}$ (April) to $27.8^{\circ} \mathrm{C}$ (August), the mean daily relative humidity ranged from $14 \%$ (May) to $89 \%$ (September), the average daily wind velocity ranged from $0.4 \mathrm{~m} / \mathrm{s}$ (October) to $4.8 \mathrm{~m} / \mathrm{s}$ (April), the amount of precipitation was $382 \mathrm{~mm}$, and monthly precipitation were $63.4 \mathrm{~mm}$ (April), $17.6 \mathrm{~mm}$ (May), $103.8 \mathrm{~mm}$ (June), $23.9 \mathrm{~mm}$ (July), 45.2 $\mathrm{mm}$ (August), $56.7 \mathrm{~mm}$ (September), $17.4 \mathrm{~mm}$ (October), respectively.

\section{Experimental design}

The study used a Uniform Design that combined eight cultivation methods (IA, PD, BN, BPS, BPM, NT, SD, GI), and each cultivation methods had five different levels. A conventional management plan and optimizing water saving plan were established as 
contrasting treatments (CK1 and CK2), bringing the total number of treatments to 27 (Table 2).

Table 2. Experimental design

\begin{tabular}{|c|c|c|c|c|c|c|c|c|}
\hline Treatments & $\begin{array}{c}\text { SD } \\
\text { (date/month) }\end{array}$ & $\begin{array}{c}\text { PD } \\
\left(\text { plants } \cdot \mathbf{h a}^{-1}\right)\end{array}$ & $\begin{array}{c}\text { BN } \\
(\mathbf{N}) \\
\left(\mathbf{k g} \cdot \mathbf{h a}^{-1}\right) \\
\end{array}$ & $\begin{array}{c}\text { BPS } \\
\left(\mathbf{P}_{2} \mathrm{O}_{5}\right) \\
\left(\mathrm{kg} \cdot \mathbf{h a}^{-1}\right) \\
\end{array}$ & $\begin{array}{c}\text { BPM } \\
\left(\mathrm{K}_{2} \mathrm{O}\right) \\
\left(\mathrm{kg} \cdot \mathrm{ha}^{-1}\right) \\
\end{array}$ & $\underset{\left(\mathbf{m}^{3} \cdot \mathbf{h} \mathbf{a}^{-1}\right)}{\mathbf{I A}}$ & $\begin{array}{c}\text { NT } \\
\left(\mathrm{kg} \cdot \mathrm{ha}^{-1}\right)\end{array}$ & $\begin{array}{c}\text { GI } \\
\text { (leaf expansion) }\end{array}$ \\
\hline 1 & 16 April & 45,000 & 150 & 225 & 300 & 60 & 600 & 18th \\
\hline 2 & 16 April & 54,000 & 0 & 75 & 300 & 120 & 1200 & 15 th \\
\hline 3 & 16 April & 63,000 & 225 & 300 & 300 & 180 & 300 & 12 th \\
\hline 4 & 16 April & 72,000 & 75 & 150 & 300 & 240 & 900 & 9th \\
\hline 5 & 16 April & 72,000 & 225 & 0 & 225 & 0 & 0 & 6 th \\
\hline 6 & 23 April & 81,000 & 75 & 300 & 225 & 120 & 900 & 6 th \\
\hline 7 & 23 April & 45,000 & 300 & 150 & 225 & 180 & 0 & 18th \\
\hline 8 & 23 April & 54,000 & 150 & 0 & 225 & 240 & 600 & 15 th \\
\hline 9 & 23 April & 63,000 & 0 & 225 & 225 & 0 & 1200 & 12th \\
\hline 10 & 23 April & 63,000 & 150 & 75 & 150 & 60 & 300 & 9th \\
\hline 11 & 29 April & 72,000 & 0 & 0 & 150 & 180 & 1200 & 9th \\
\hline 12 & 29 April & 81,000 & 225 & 225 & 150 & 240 & 300 & 6th \\
\hline 13 & 29 April & 45,000 & 75 & 75 & 150 & 0 & 900 & 18th \\
\hline 14 & 29 April & 54,000 & 300 & 300 & 150 & 60 & 0 & 15 th \\
\hline 15 & 29 April & 54,000 & 75 & 150 & 75 & 120 & 600 & 12 th \\
\hline 16 & 6 May & 63,000 & 300 & 75 & 75 & 240 & 0 & 12 th \\
\hline 17 & 6 May & 72,000 & 150 & 300 & 75 & 0 & 600 & 9th \\
\hline 18 & 6 May & 81,000 & 0 & 150 & 75 & 60 & 1200 & 6th \\
\hline 19 & 6 May & 45,000 & 225 & 0 & 75 & 120 & 300 & 18th \\
\hline 20 & 6 May & 45,000 & 0 & 225 & 0 & 180 & 900 & 15 th \\
\hline 21 & 13 May & 54,000 & 225 & 150 & 0 & 0 & 300 & 15 th \\
\hline 22 & 13 May & 63,000 & 75 & 0 & 0 & 60 & 900 & 12th \\
\hline 23 & 13 May & 72,000 & 300 & 225 & 0 & 120 & 0 & 9th \\
\hline 24 & 13 May & 81,000 & 150 & 75 & 0 & 180 & 600 & 6 th \\
\hline 25 & 13 May & 81,000 & 300 & 300 & 300 & 240 & 1200 & 18th \\
\hline CK1 & 29 April & 72,000 & 375 & 180 & 150 & 0 & 1200 & 11th \\
\hline CK2 & 29 April & 72,000 & 225 & 180 & 150 & 150 & $600 / 750$ & 9th/11th \\
\hline
\end{tabular}

Note: sowing date (SD), planting density (PD), base nitrogen (BN), base phosphorus (BPS), base potassium (BPM), irrigation amount (IA), topdressing (NT), growth stages of irrigation (GI)

The Uniform Design was a new experimental design method, it was found by Chinese scholars Fang $\mathrm{K}$ and Wang $\mathrm{Y}$ and won the second prize of State Natural Science Award in 2008. The advantage of it was the factors levels can be increased largely, but the treatments were decreased. At present the total number of citations recognized by SCI is more than 700, and it would be more and more widely used in practices (Jia et al., 2011; Maria et al., 2016; Zhou et al., 2019).

The plot area was $30 \mathrm{~m}^{2}(60 \mathrm{~cm} \times 50 \mathrm{~cm})$, and plants were grown in rows spaced $60 \mathrm{~cm}$ apart. There was a 1-m space between plots in order to minimize irrigation water spreading among treatments, and irrigation was controlled by raised ridges between the plots. Across the maize growth stages, cultivation methods were applied to all plots in accordance with the design, and conventional field management methods, including intertillage, weed, pest, and disease controls, and suitable harvest times, were used to regulate growth (Figure 1). 


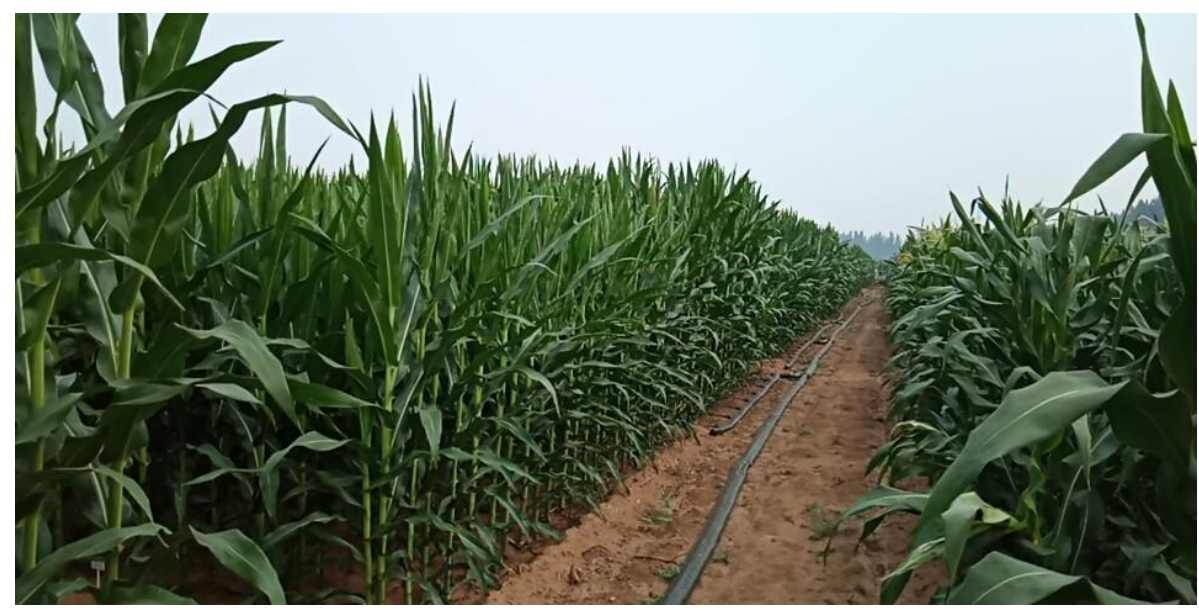

Figure 1. Irrigation and plots of the field experiment

The applied maize variety name was 'Dafeng 30', which was the main cultivar in this district in recent years. The tillage methods was crushed maize straw and returned to the field after harvest in autumn of last year and made preparations for plough and sowing in spring. The seeds had been coated to prevent pest and disease and herbicides were applied after sowing for plant protection.

\section{Experimental measurements}

\section{Subheading Soil water content}

The soil water content of 20-cm-deep cores from depths ranging from 0 to $200 \mathrm{~cm}$ were measured using the oven-drying method at maize stages corresponding to the expansion of the 6th, 9th, 12th, and 15th leaf, silking, 15 and 30 days after silking, and harvest, respectively. Each sample was taken by soil auger, and after being weighed, soil samples were dried for $24 \mathrm{~h}$ at $105^{\circ} \mathrm{C}$. Oven-dried weight was then determined, followed by the calculation of gravimetric soil water content, which is [(wet soil weight) - (dry soil weight)] / (dry soil weight). Volumetric soil water content was then determined by multiplying the gravimetric soil water content by the respective bulk density at each sample depth, as shown in Table 1. The water content of each layer was converted to $\mathrm{mm}$ and summed to obtain the soil water content of the $0-200-\mathrm{cm}$-deep soil profile.

\section{Water consumption}

Water consumption (WC) was determined using the following field water balance equation:

$$
W C=\Delta W_{X}+I+P+G
$$

Here, $W C$ is the water consumption $(\mathrm{mm}), I$ is the irrigation amount $(\mathrm{mm}), P$ is the effective precipitation, $\Delta W_{x}$ is the difference in soil water content of the $0-200$-cm soil depth between the beginning and end of maize growing season, $G$ is the groundwater 
supplementary amount, which can be considered as negligible because of the deep water table level $(80 \mathrm{~m})$.

Water use efficiency

Water use efficiency (WUE) was calculated using the following equation:

$$
W U E=Y / W C
$$

Here, $Y$ is the grain yield ( $\mathrm{kg} / \mathrm{ha})$, and $W C$ is again the water consumption over the whole growing season $(\mathrm{mm})$.

\section{Maize yield}

Ears were harvested from the two central rows of each plot, dried, and shelled. Unshelled ear samples were also taken from experimental plots, and the ear length, ear diameter, number of kernel rows, kernels per row, and hundred-kernel-weight per ear were recorded, respectively; each ear sample was composed of 10 healthy ears from the central rows of each plot. The total yield was then extrapolated based on these results.

\section{Statistical analysis}

Data were analyzed using Excel 2007 (Microsoft Corp., Redmond, WA, USA) and SPSS statistical analysis software (IBM Corp., Armonk, NY, USA). Correlation analysis and regression were used to determine the effects of cultivation on WC and WUE, respectively. Statistical significance was assessed at probability thresholds of $p<0.05$ and $p<0.01$.

\section{Results}

\section{Effects of treatments on WC and WUE}

As shown in Table 3, WC and WUE differed among treatments, with respective maximum ranges of $141.8 \mathrm{~mm}$ between treatments 4 and 1 and of $7.7 \mathrm{~kg} \cdot \mathrm{ha}^{-1} \cdot \mathrm{mm}^{-1}$ between treatments 24 and 8 . While WC was higher for the CK group than for all others, WUE for the CK group was lower than that for all other groups. Accordingly, WC and WUE under each treatment were analyzed to determine a superior irrigation plan for this region.

\section{Analysis of correlations and interaction effects of cultivation methods on WC}

IA had positive and significant $(p<0.01)$ correlations with WC (Table 4$)$, the index of correlation (IC) values reached 0.74 , demonstrating that WC increase with IA in this region (Figure 2), likely because water absorbed and used by maize was efficiently increased by irrigation. And by analyzing the correlations between yield and WC (Figure 2), water was apparently mainly used for maize transpiration, with little field evaporation; thus, WC and yield increased together. 
Table 3. Water consumption (WC) and water use efficiency (WUE) of treatments

\begin{tabular}{c|c|c|c|c|c|c|c|c}
\hline Treatments & $\begin{array}{c}\mathbf{W C} \\
(\mathbf{m m})\end{array}$ & $\begin{array}{c}\text { WUE } \\
\left(\mathbf{k g} \cdot \mathbf{h a}^{-\mathbf{1}} \cdot \mathbf{m m}^{-\mathbf{1}}\right)\end{array}$ & Treatments & $\begin{array}{c}\mathbf{W C} \\
(\mathbf{m m})\end{array}$ & $\begin{array}{c}\mathbf{W U E} \\
\left(\mathbf{k g} \cdot \mathbf{h a}^{-\mathbf{1}} \cdot \mathbf{m m}^{-\mathbf{1}}\right)\end{array}$ & Treatments & $\begin{array}{c}\mathbf{W C} \\
(\mathbf{m m})\end{array}$ & $\begin{array}{c}\mathbf{W U E} \\
\left(\mathbf{k g} \cdot \mathbf{h} \mathbf{a}^{-\mathbf{1}} \cdot \mathbf{m m}^{-\mathbf{1}}\right)\end{array}$ \\
\hline $\mathbf{1}$ & 428.2 & 25.8 & $\mathbf{1 0}$ & 474.7 & 27.0 & $\mathbf{1 9}$ & 475.2 & 24.8 \\
$\mathbf{2}$ & 555.1 & 24.8 & $\mathbf{1 1}$ & 466.4 & 26.3 & $\mathbf{2 0}$ & 479.5 & 23.2 \\
$\mathbf{3}$ & 548.3 & 24.3 & $\mathbf{1 2}$ & 503.7 & 27.3 & $\mathbf{2 1}$ & 542.9 & 23.2 \\
$\mathbf{4}$ & 570.8 & 25.8 & $\mathbf{1 3}$ & 433.8 & 25.7 & $\mathbf{2 2}$ & 487.8 & 26.3 \\
$\mathbf{5}$ & 490.0 & 25.8 & $\mathbf{1 4}$ & 457.8 & 27.4 & $\mathbf{2 3}$ & 500.9 & 25.7 \\
$\mathbf{6}$ & 512.3 & 27.2 & $\mathbf{1 5}$ & 470.7 & 27.4 & $\mathbf{2 4}$ & 446.4 & 30.1 \\
$\mathbf{7}$ & 488.9 & 26.6 & $\mathbf{1 6}$ & 523.7 & 25.3 & $\mathbf{2 5}$ & 489.6 & 26.9 \\
$\mathbf{8}$ & 537.1 & 22.4 & $\mathbf{1 7}$ & 467.9 & 28.6 & $\mathbf{C K 1}$ & 535.2 & 26.9 \\
$\mathbf{9}$ & 479.6 & 29.7 & $\mathbf{1 8}$ & 513.7 & 24.7 & $\mathbf{C K 2}$ & 573.8 & 24.9 \\
\hline
\end{tabular}

Table 4. Analyze of correlation between water consumption (WC) and cultivation methods

\begin{tabular}{|c|c|c|c|c|c|c|c|c|c|}
\hline IC & $\begin{array}{c}\text { SD } \\
\text { (date/month) }\end{array}$ & $\begin{array}{c}\text { PD } \\
\left(\text { plants } \cdot \mathbf{h a}^{-1}\right)\end{array}$ & $\begin{array}{c}\text { BN } \\
(\mathbf{N}) \\
\left(\mathbf{k g} \cdot \mathbf{h a}^{-1}\right) \\
\end{array}$ & $\begin{array}{c}\text { BPS } \\
\left(\mathrm{P}_{2} \mathrm{O}_{5}\right) \\
\left(\mathrm{kg}^{-} \mathbf{h a}^{-1}\right) \\
\end{array}$ & $\begin{array}{c}\text { BPM } \\
\left(\mathrm{K}_{2} \mathrm{O}\right) \\
\left(\mathrm{kg}^{2} \mathbf{h a}^{-1}\right) \\
\end{array}$ & $\begin{array}{c}\text { NT } \\
\left(\mathrm{kg}^{\prime} \cdot \mathrm{ha}^{-1}\right)\end{array}$ & $\underset{\left(\mathbf{m}^{3} \cdot \mathbf{h} \mathbf{a}^{-1}\right)}{\mathbf{I A}}$ & $\begin{array}{c}\text { GI } \\
\text { (leaf expansion) }\end{array}$ & Yield \\
\hline WC & -0.22 & 0.2 & 0.01 & 0 & 0.25 & 0.05 & $0.74 * *$ & -0.27 & $0.53^{* *}$ \\
\hline
\end{tabular}

Note: $* p<0.05$, ** $p<0.01$, index of correlation (IC), sowing date (SD), planting density (PD), base nitrogen (BN), base phosphorus (BPS), base potassium (BPM), irrigation amount (IA), topdressing (NT), growth stages of irrigation (GI)
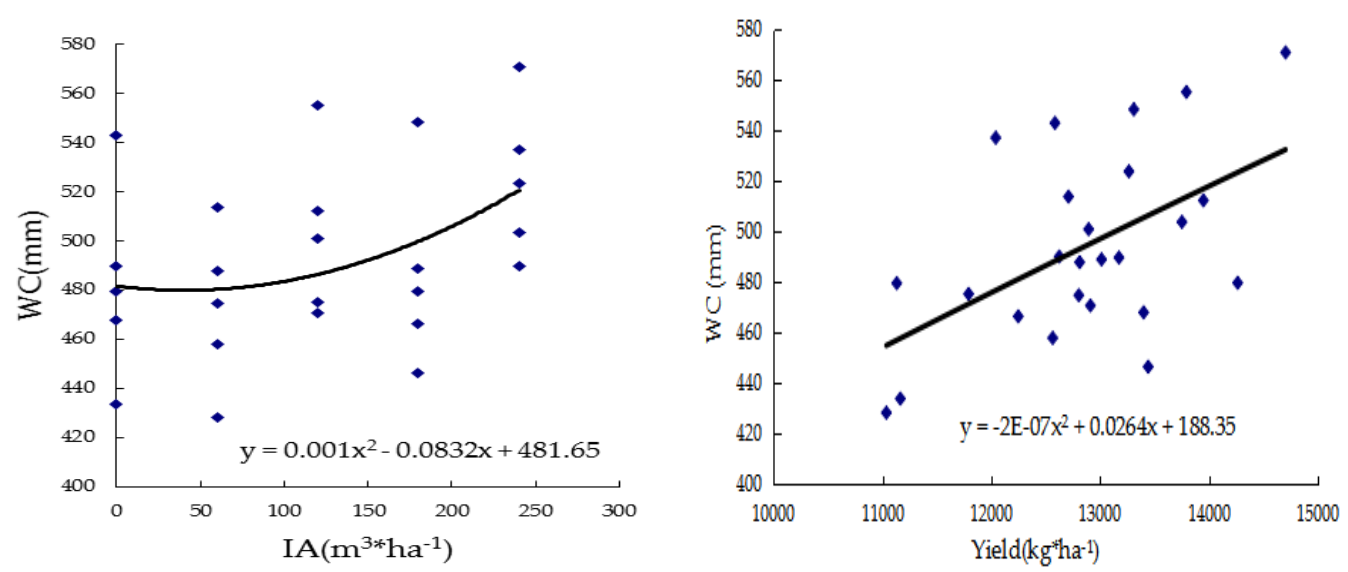

Figure 2. Correlation analysis for water consumption $(W C)$ and yield with irrigation amount (IA)

Quadratic polynomial stepwise regression analysis (Table 5) revealed that IA and GI as well as BN and BPM had positive and significant interaction effects on yield, respectively $(p<0.01)$. Through further assessment with path analysis and comparisons of direct path coefficients, we found that the interaction effect of IA and GI was highest, with a direct path coefficient (DPC) of 0.69 , and interaction effects of the other interaction effects, $\mathrm{PD} \times \mathrm{BN}$ and $\mathrm{BN} \times \mathrm{BPM}$, had $\mathrm{DPC}$ values of 0.46 and 0.27 , respectively, indicating little effect on WC. Accordingly, growth stage should be considered when developing irrigation plans in this region in order to optimize irrigation. 
Table 5. Test results and path analysis of water consumption (WC) model regression index

\begin{tabular}{c|c|c|c|c}
\hline Agricultural factors & Partial correlation & $\boldsymbol{t}$-test value & $\boldsymbol{p}$-value & Direct path analysis \\
\hline IA & 0.8699 & 7.8878 & 0.0001 & 1.3889 \\
PD $\times$ BN & 0.4104 & 2.0125 & 0.0572 & 0.2787 \\
BN $\times$ BPM & -0.5864 & 3.2378 & 0.0039 & -0.4555 \\
IA $\times$ GI & -0.6618 & 3.9481 & 0.0007 & -0.6872 \\
\hline
\end{tabular}

Note: planting density (PD), base nitrogen (BN), base potassium (BPM), irrigation amount (IA), growth stages of irrigation $(\mathrm{GI})$

\section{Analysis of correlations and interaction effects of cultivation methods on WUE}

WUE improvement is a key focus of maize research. As shown in Table 6, PD had a positive significant correlation with WUE; the IC value was 0.42 ; and further analysis found that WUE had a negative significant correlation with WC (Figure 3). This demonstrated that PD increases could increase WUE significantly in this region, likely because field evaporation can be reduced by increased PD during maize seedling stage; furthermore, the limited water resource use efficiency was improved.

Table 6. Correlation analysis for water use efficiency (WUE) and cultivation methods

\begin{tabular}{|c|c|c|c|c|c|c|c|c|c|c|}
\hline IC & $\begin{array}{c}\text { SD } \\
\text { (date/month) }\end{array}$ & $\begin{array}{c}\text { PD } \\
\left(\text { plants }^{\prime} \mathbf{h a}^{-1}\right)\end{array}$ & $\begin{array}{c}\text { BN (N) } \\
\left(\mathbf{k g}^{\prime} \cdot \mathbf{h a} \mathbf{a}^{-1}\right)\end{array}$ & $\begin{array}{c}\text { BPS } \\
\left(\mathbf{P}_{2} \mathrm{O}_{5}\right) \\
\left(\mathrm{kg} \cdot \mathrm{ha}^{-1}\right)\end{array}$ & $\begin{array}{c}\text { BPM } \\
\left(\mathrm{K}_{2} \mathrm{O}\right) \\
\left(\mathrm{kg} \cdot \mathbf{h a}^{-1}\right)\end{array}$ & $\left|\begin{array}{c}\text { NT } \\
\left(\mathrm{kg}^{\prime} \cdot \mathrm{ha}^{-1}\right)\end{array}\right|$ & $\begin{array}{c}\text { IA } \\
\left(\mathbf{m}^{3} \cdot \mathbf{h a}^{-1}\right)\end{array}$ & \begin{tabular}{|c}
$\begin{array}{c}\text { GI } \\
\text { (leaf } \\
\text { expansion) }\end{array}$ \\
\end{tabular} & ield & WC \\
\hline WUE & 0.08 & $0.42 *$ & -0.01 & 0.26 & -0.02 & 0.01 & -0.26 & 0.22 & $0.47 *$ & $-0.50 * *$ \\
\hline
\end{tabular}

Note: $* p<0.05, * * p<0.01$, water consumption (WC), index of correlation (IC), sowing date (SD), planting density (PD), base nitrogen (BN), base phosphorus (BPS), base potassium (BPM), irrigation amount (IA), topdressing (NT), growth stages of irrigation (GI)
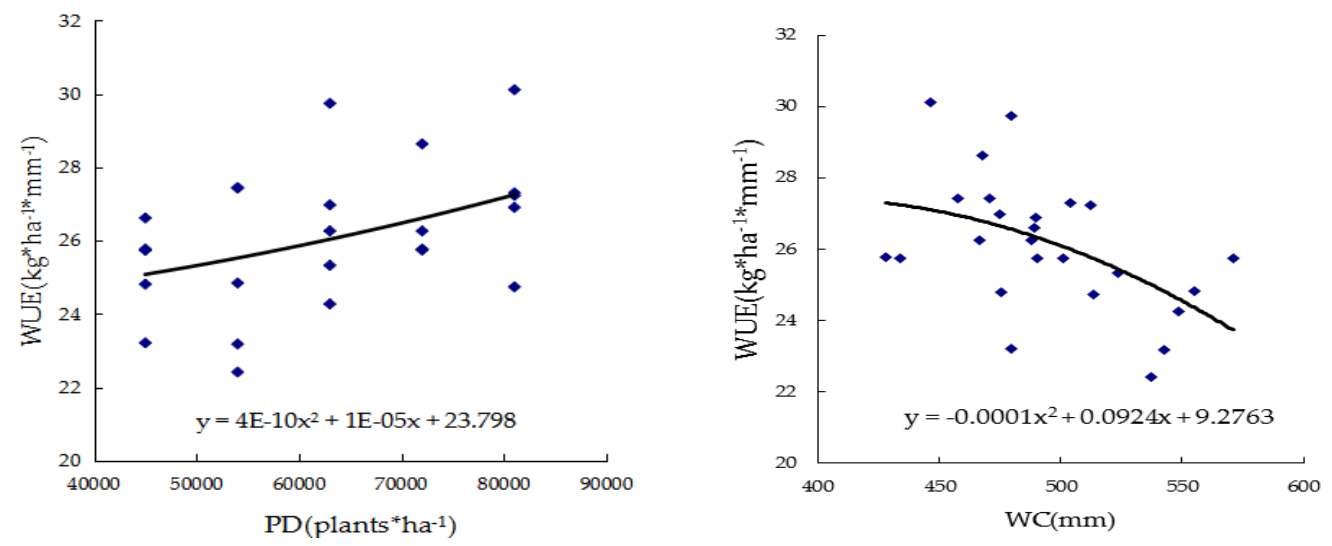

Figure 3. Correlation analysis for water use efficiency (WUE) with planting density (PD) and water consumption $(W C)$

The effect of agricultural factors on WUE summarized in Table 7 is based on quadratic polynomial stepwise regression analysis, with only BPS and GI having positive and significant interaction effects on WUE $(p<0.05)$. Path analysis and a comparison of direct path coefficients revealed that the interaction effect of BPS and GI was higher than that of the others, with a DPC of 0.37. The interaction effect of SD and IA was lower than that of BPS and GI, with a DPC of only 0.29; this was possibly 
explained by maize root growth not being improved by increased BPS, and thus deep soil water could not be absorbed. Meanwhile, when GI was conducted at the critical demand stage, WUE was improved effectively.

Table 7. Test results and path analysis for water use efficiency (WUE) model regression index

\begin{tabular}{c|c|c|c|c}
\hline Agricultural factors & Partial correlation & $\boldsymbol{t}$-test value & $\boldsymbol{p}$-value & Direct path analysis \\
\hline $\mathrm{PD} \times \mathrm{PD}$ & 0.4659 & 2.4126 & 0.0246 & 0.4204 \\
$\mathrm{SD} \times \mathrm{IA}$ & -0.3399 & 1.656 & 0.1119 & -0.2902 \\
$\mathrm{BPS} \times \mathrm{GI}$ & 0.4192 & 2.116 & 0.0459 & 0.3703 \\
\hline
\end{tabular}

Note: planting density (PD), sowing date (SD), base phosphorus (BPS), irrigation amount (IA), growth stages of irrigation $(\mathrm{GI})$

\section{Optimizing statistical model of yield}

The yields of different treatments are shown in Table 8. Quadratic polynomial stepwise regression analysis revealed the following statistical model describing the relationship between the cultivation methods and yield:

$$
\begin{aligned}
& Y=-96.82+5.37 P D-0.00054 P D * P D+0.44 I A * I A-0.0067 P D * I A \\
& -2.88 B N * N T+3.19 B P S * N T+2.13 I A * G I
\end{aligned}
$$

\begin{tabular}{|c|c|c|c|c|c|c|c|}
\hline Treatments & $\begin{array}{l}\text { Ear length } \\
\text { (cm) }\end{array}$ & $\begin{array}{c}\text { Ear } \\
\text { diameter } \\
(\mathbf{m m}) \\
\end{array}$ & \begin{tabular}{|c|}
$\begin{array}{c}\text { Number of } \\
\text { kernel rows } \\
\text { (rows) }\end{array}$ \\
\end{tabular} & \begin{tabular}{|c|}
$\begin{array}{c}\text { Kernels per } \\
\text { row } \\
\text { (kernels) }\end{array}$ \\
\end{tabular} & \begin{tabular}{|c|}
$\begin{array}{c}\text { Hundred kernel } \\
\text { weight per ear } \\
(\mathrm{g})\end{array}$ \\
\end{tabular} & 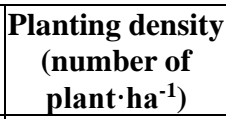 & $\begin{array}{c}\text { Yield } \\
\left(\mathrm{kg}^{2} \cdot \mathrm{ha}^{-1}\right)\end{array}$ \\
\hline 1 & 20.5 & 5.05 & 17 & 39 & 37.43 & 45000 & 11035.5 \\
\hline 2 & 20.5 & 5.00 & 16 & 40 & 39.11 & 54000 & 13792.5 \\
\hline 3 & 20.6 & 4.98 & 17 & 34 & 38.09 & 63000 & 13309.5 \\
\hline 4 & 18.0 & 4.77 & 15 & 37 & 35.69 & 72000 & 14704.5 \\
\hline 5 & 17.0 & 6.56 & 15 & 33 & 35.14 & 72000 & 12624.0 \\
\hline 6 & 16.8 & 4.73 & 17 & 30 & 34.58 & 81000 & 13948.5 \\
\hline 7 & 20.8 & 5.01 & 16 & 47 & 38.86 & 45000 & 13012.5 \\
\hline 8 & 20.3 & 4.87 & 16 & 38 & 36.87 & 54000 & 12040.5 \\
\hline 9 & 20.3 & 4.87 & 15 & 39 & 38.45 & 63000 & 14263.5 \\
\hline 10 & 18.9 & 4.72 & 16 & 38 & 33.59 & 63000 & 12804.0 \\
\hline 11 & 17.7 & 4.82 & 16 & 33 & 32.08 & 72000 & 12247.5 \\
\hline 12 & 19.0 & 4.85 & 16 & 29 & 36.18 & 81000 & 13752.0 \\
\hline 13 & 20.2 & 7.27 & 16 & 43 & 35.83 & 45000 & 11164.5 \\
\hline 14 & 20.5 & 4.94 & 16 & 39 & 38.04 & 54000 & 12564.0 \\
\hline 15 & 20.4 & 4.87 & 17 & 40 & 36.14 & 54000 & 12910.5 \\
\hline 16 & 19.7 & 5.00 & 17 & 36 & 34.82 & 63000 & 13264.5 \\
\hline 17 & 20.0 & 5.02 & 16 & 35 & 33.09 & 72000 & 13399.5 \\
\hline 18 & 16.7 & 4.46 & 17 & 31 & 30.73 & 81000 & 12709.5 \\
\hline 19 & 22.0 & 5.18 & 17 & 39 & 40.15 & 45000 & 11791.5 \\
\hline 20 & 20.8 & 5.14 & 17 & 40 & 37.43 & 45000 & 11131.5 \\
\hline 21 & 20.3 & 5.03 & 17 & 38 & 36.09 & 54000 & 12585.0 \\
\hline 22 & 18.9 & 4.87 & 17 & 37 & 32.49 & 63000 & 12811.5 \\
\hline 23 & 17.7 & 4.78 & 16 & 35 & 32.00 & 72000 & 12894.0 \\
\hline 24 & 16.2 & 4.79 & 16 & 31 & 32.70 & 81000 & 13441.5 \\
\hline 25 & 18.1 & 4.84 & 17 & 31 & 31.30 & 81000 & 13173.0 \\
\hline CK1 & 18.3 & 4.74 & 16 & 36 & 34.15 & 72000 & 14415.0 \\
\hline $\mathrm{CK} 2$ & 19.2 & 4.63 & 17 & 35 & 34.17 & 72000 & 14313.0 \\
\hline
\end{tabular}

Table 8. Yields and yield characters of different treatments 
The optimizing results showed when the SD was 16 April, PD was 72000 plants $\cdot \mathrm{ha}^{-1}$, BN was $0 \mathrm{~kg} \cdot \mathrm{ha}^{-1}$, BPS was $300 \mathrm{~kg} \cdot \mathrm{ha}^{-1}$, BPM was $250 \mathrm{~kg} \cdot \mathrm{ha}^{-1}$, NT was $240 \mathrm{~kg} \cdot \mathrm{ha}^{-1}$, IA was $1200 \mathrm{~m}^{3} \cdot \mathrm{ha}^{-1}$, and GI was maize at the $18^{\text {th }}$ leaf expansion stage, the highest theoretical value of $15,458.75 \mathrm{~kg} \cdot \mathrm{ha}^{-1}$ was reached.

While most scholars recognized that increased $\mathrm{N}$ fertilizer can be very useful for improving maize yields, in this study, the optimizing model revealed that $\mathrm{BN}$ was not needed. This may be explained by the soil base $\mathrm{N}$ being sufficient for maize seedling growth, perhaps demonstrating that excess $\mathrm{N}$ fertilizer had been used on the field previously; alternatively, $\mathrm{N}$ might have leached into the field from polluted groundwater. Accordingly, groundwater pollution should be considered, and less fertilizer $\mathrm{N}$ should be used compared with that often considered necessary for maximum maize yields.

\section{Discussion}

Water consumption is a research focus in water-limited regions, and it is affected by many cultivation factors. Generally, WC can be equal to crop evapotranspiration in agricultural fields. Many studies have confirmed that irrigation has substantial effects on evapotranspiration. For example, in Kirklareli, Turkey, seasonal evapotranspiration of maize ranges from $762 \mathrm{~mm}$ under full irrigation to $265 \mathrm{~mm}$ in unirrigated fields (Cakir, 2004). Similarly, in Aydin, Turkey, seasonal evapotranspiration of closed-end furrow irrigated maize ranged from $558 \mathrm{~mm}$ under full irrigation to $174 \mathrm{~mm}$ in unirrigated fields (Dagdelen et al., 2006). In Nebraska, USA, seasonal evapotranspiration in maize varied between $625 \mathrm{~mm}$ and $366 \mathrm{~mm}$ depending on different irrigation treatments (Payero et al., 2006). In our study, WC under different treatments ranged from $570.8 \mathrm{~mm}$ to $428.2 \mathrm{~mm}$, and effective irrigation management was useful in decreasing crop water consumption through selecting proper IA and GI. Identifying the most sensitive growth stage of irrigation was also an important way to enhance crop productivity while keeping WC low. Additionally, linear relationships between maize yield and evapotranspiration, which was the same as WC in our study, have been reported by Payero and Djaman, akin to our results (Payero et al., 2009; Djaman and Irmak, 2013).

In arid regions, an understanding of WUE is essential for evaluating crops when water resources are a limiting factor. Many studies have indicated that low irrigation is one way to maximize water use efficiency for higher yields per unit of irrigation water applied in arid and semiarid regions (Bekele and Tilahun, 2007). However, under water limitation, other cultivation factors (e.g., soil fertility, tillage, and soil composition) have a significant role in enhancing crop water productivity (Molden et al., 2009). For example, amending soil with biochar under limited water supply might be a novel approach for enhancing maize yield and water use efficiencies by minimizing the negative impact of drought stress (Faloye et al., 2019). In our study, WUE values were improved by increasing PD, while yield was also increased, but was negatively correlated with WC. Additionally, proper BPS and GI selection can improve maize WUE, achieving an ideal root type for improved water and P-uptake in maize, as has been reported (Lynch, 2013). Accordingly, this would be an appropriate direction for future research as a means of improving water resource utilization.

Increasing maize yields has long been an important research topic. The present study examined eight cultivation methods, with each measure consisting of five levels. Using 
a traditional design method, such field tests can be very complicated and difficult to realize, but by adopting a uniform design and dynamic adjustment method, this situation can be examined effectively with the impact of each measure accurately evaluated. Finally, through processing experimental data and regression analysis, effective cultivation methods were established, which suggest conditions for optimal maize yields.

\section{Conclusions}

In eight different cultivation methods of our study, Firstly, IA had a significant impact on WC, and the interaction effect of IA and GI could significantly affect WC; Secondary, PD had the greatest impact on WUE, and BPS and GI had the obviously interaction effect on WUE; thus, we should reduce WC while increasing WUE in maize production, and need to focus on IA and PD and GI and BPS; Finally, we found that when the SD was 16 April, PD was 72000 plants $\bullet \mathrm{ha}^{-1}$, BN was $0 \mathrm{~kg} \bullet \mathrm{ha}^{-1}$, BPS was $300 \mathrm{~kg} \bullet \mathrm{ha}^{-1}$, BPM was $250 \mathrm{~kg} \bullet \mathrm{ha}^{-1}$, NT was $240 \mathrm{~kg} \bullet \mathrm{ha}^{-1}$, IA was $1200 \mathrm{~m} 3 \bullet \mathrm{ha}^{-1}$, and GI was maize at the 18th leaf expansion stage, the maize yield could reached $15,458.75 \mathrm{~kg} \bullet \mathrm{ha}^{-1}$, but it was the theoretical value, and need to test in practices in future.

While maize yield has been continuously improved in China, agricultural water consumption has also increased. Consequently, the groundwater level has been continuously falling, and water overexploitation has become a serious issue. Accordingly, discovering approaches to balancing water resource used and yield production in northern arid regions of China has become important. As growth and metabolism processes consume more water, drought stress-sensitive stages and optimized irrigation schedules should be consider specially when planning irrigation. The present research can be refined through more years of experimentation at the site in order to validate the suitability of this model to different environmental conditions.

Acknowledgements. This research was financially supported by the National Natural Science Foundation of China (41572239), the National Public Project of China Ministry of Agricultural (201503124), the Shanxi Key Research and Development Projects (201703D211002), the Shanxi Academy of Agricultural Sciences Foundation (YGG1639), Organic Dry Farming of Shanxi Province Key Laboratory (201805D111015). We would also like to thank all the staff for technical assistance in carrying out the field experiments.

\section{REFERENCES}

[1] Ahadi, R., Samani, Z., Skaggs, R. (2013): Evaluating on-farm irrigation efficiency across the watershed: a case study of New Mexico's Lower Rio Grande Basin. - Agricultural Water Management 124: 52-57.

[2] Bekele, S., Tilahun, K. (2007): Regulated deficit irrigation scheduling of onion in a semiarid region of Ethiopia. - Agricultural Water Management 98: 148-152.

[3] Cakir, R. (2004): Effect of water stress at different development stages on vegetative and reproductive growth of corn. - Field Crop Research 89(1): 1-16.

[4] Cucci, G., Lacolla, G., Boari, F., Mastro, M. A., Cantore, V. (2019): Effect of water salinity and irrigation regime on maize (Zea mays L.) cultivated on clay loam soil and irrigated by furrow in Southern Italy. - Agricultural Water Management 222: 118-124. 
[5] Dagdelen, N., Yilmaz, E., Sezgin, F., Talih, G. (2005): Water-yield relation and water use efficiency of cotton and second crop corn in western Turkey. - Agricultural Water Management 82(1): 63-85.

[6] Djaman, K., Irmak, S. (2013): Actual crop evapotranspiration and alfalfa and grassreference crop coefficients of maize under full and limited irrigation and rainfed conditions. - Journal of Irrigation \& Drainage Engineering 139: 433-446.

[7] Dong, Y. Y., Wang, B. C., Jia, L. H., Mu, H. W., Fei, L. J. (2014): Study on the water consumption characteristics and efficiency of summer corn under film hole water production irrigation. - Agricultural Research of Arid Areas 32: 7-12.

[8] Dong, Q. G., Yang, Y., Yu, K., Feng, H. (2018): Effects of straw mulching and plastic film mulching on improving soil organic carbon and nitrogen fractions, crop yield and water use efficiency in the Loess Plateau, China. - Agricultural Water Management 201: 133-143.

[9] Faloye, O. T., Alatise, M. O., Ajayi, A. E., Ewulo, B. S. (2019): Effects of biochar and inorganic fertilizer application on growth, yield and water use efficiency of maize under deficit irrigation. - Agricultural Water Management 217: 165-178.

[10] Fan, Y. Q., Ding, R. S., Kang, S. Z., Hao, X. M., Du, T. S., Tong, L., Li, S. E. (2017): Plastic mulch decreases available energy and evapotranspiration and improves yield and water use efficiency in an irrigated maize cropland. - Agricultural Water Management 179: 122-131.

[11] Feng, Y., Hao, W. P., Gao, L. L., Li, H. R., Gong, D. Z., Cui, N. B. (2019): Comparison of maize water consumption at different scales between mulched and non-mulched croplands. - Agricultural Water Management 216: 315-324.

[12] Han, M., Zhang, H. H., Kendall, C. D., Louise, H. C., Thomas, J. T. (2016): Estimating maize water stress by standard deviation of canopy temperature in thermal imagery. Agricultural Water Management 177: 400-409.

[13] Huynh, H. T., Hufnagel, J., Wurbs, A., Bellingrath-Kimura, S. D. (2019): Influences of soil tillage, irrigation and crop rotation on maize biomass yield in a 9-year field study in Müncheberg, Germany. - Field Crop Research 241: 107565.

[14] Jia, L. P., Wang, Y. P., Fan, L. (2011): Uniform Design Based Hybrid Genetic Algorithm for Multiobjective Bilevel Convex Programming. - Computational Intelligence and Security (CIS), Seventh International Conference.

[15] Liu, T. D., Song, F. B., Liu, S. Q., Zhu, X. C. (2012): Light interception and radiation use efficiency response to narrow-wide row planting patterns in maize. - Australian Journal of Crop Science 6(3): 506-513.

[16] Liu, Y., Gao, M. S., Wu, W., Sikander, K. T., Wen, X. X., Liao, Y. C. (2013): The effects of conservation tillage practices on the soil water-holding capacity of a non-irrigated apple orchard in the Loess Plateau, China. - Soil Tillage Research 130: 7-12.

[17] Lynch, J. P. (2013): Steep, cheap and deep: an ideotype to optimize water and N acquisition by maize root systems. - Annals of Botany 112: 347-357.

[18] Molden, D., Oweis, T., Steduto, P., Bindraban, P., Hanjra, M. A., Kijne, J. (2009): Improving agricultural water productivity: between optimism and caution. - Agricultural Water Management 97(4): 528-535.

[19] Ogola, J. B. O., Wheeler, T. R., Harris, P. M. (2007): Predicting the effects of nitrogen and planting density on maize water use in semi-arid Kenya. - South African Journal of Plant and Soil 24(1): 51-57.

[20] Payero, J. O., Melvin, S. R., Irmak, S., Tarkalson, D. (2006): Yield response of corn to deficit irrigation in a semiarid climate. - Agricultural Water Management 84(1): 101-112.

[21] Payero, J. O., Tarkalson, D. D., Irmak, S., Davison, D., Petersen, J. L. (2009): Effect of timing of a deficit-irrigation allocation on corn evapotranspiration, yield, water use efficiency and dry mass. - Agricultural Water Management 96(10): 1387-1397. 
[22] Pereira, L. S., Cordery, I., Iacovides, I. (2012): Improved indicators of water use performance and productivity for sustainable water conservation and saving. Agricultural Water Management 108: 39-51.

[23] Rajbir, K., Arora, V. K. (2019): Deep tillage and residue mulch effects on productivity and water and nitrogen economy of spring maize in north-west India. - Agricultural Water Management 213: 724-731.

[24] Sayed, A., Sarker, A., Kim, J.-E., Rahman, M., Mahmud, G. A. (2019): Environmental sustainability and water productivity on conservation tillage of irrigated maize in red brown terrace soil of Bangladesh. - Journal of the Saudi Society of Agricultural Sciences 03: 002.

[25] Shanxi Provincial Bureau of Statistics \& Survey Office of the National Bureau of Statistics in Shanxi. (2016): Shanxi Statistical Yearbook. - China Statistics Press, Beijing 34.

[26] Takahashi, M. B., Rocha, J. C., Núnez, E. G. F. (2016): Optimization of artificial neural network by genetic algorithm for describing viral production from uniform design data. Process Biochemistry 51(3): 422-430.

[27] Wang, S. S., Liu, D. X., Wang, K. S., Meng, P. T. (2015): Fuzzy comprehensive evaluation on water consumption characteristics and yield of summer corn under different furrow irrigation patterns. - Transactions of the Chinese Society of Agricultural Engineering 31(24): 89-94.

[28] Yang, L., Yang, Y. Z., Feng, Z. M., Zheng, Y. N. (2016): Effect of maize sowing area changes on agricultural water consumption from 2000 to 2010 in the West Liaohe Plain, China. - Journal of Integrative Agriculture 15(6): 1407-1416.

[29] Yang, J., Mao, X. M., Wang, K., Yang, W. C. (2018): The coupled impact of plastic film mulching and deficit irrigation on soil water/heat transfer and water use efficiency of spring wheat in Northwest China. - Agricultural Water Management 201: 232-245.

[30] Yu, J. L., Nie, L. X., Zheng, H. B., Zhang, W. J., Song, Z. W., Tang, J. H., Lin, Z. Q., Qi, H. (2013): Effect of matter production and yield formation on sowing date and density in maize. - Journal of Maize Sciences 21(5): 76-80.

[31] Zeng, Z., Gower, D. B., Wood, E. F. (2018): Accelerating forest loss in Southeast Asian Massif in the 21st century: a case study in Nan Province, Thailand. - Global Change Biology 24(10): 4682-4695.

[32] Zhang, D. M., Zhang, W., Chen, Q., Huang, X. F., Jiang, C. X., Han, Y. L., Liu, E. K., Chi, B. L. (2014): Effects of planting density on plant traits and water consumption characteristics of dryland maize. - Journal of Maize Sciences 22: 102-108.

[33] Zhang, F., Zhang, W. J., Qi, J. G., Li, F. M. (2018): A regional evaluation of plastic film mulching for improving crop yields on the Loess Plateau of China. - Agricultural and Forest Meteorology 248: 458-468.

[34] Zhao, Y. L., Xue, Z. W., Guo, H. B., Mu, X. Y., Li, C. H. (2014): Effects of tillage and straw returning on water consumption characteristics and water use efficiency in the winter wheat and summer maize rotation system. - Scientia Agricultura Sinica 47(17): 3359-3371.

[35] Zhou, Y., Wang, J. Y., Gao, X. J., Wang, K., Wang, W. W., Wang, Q., Yan, P. S. (2019): Isolation of a novel deep-sea Bacillus circulus strain and uniform design for optimization of its anti-aflatoxigenic bioactive metabolites production. - Bioengineered 10(1): 13-22. 